\title{
Selection Vector for Direct Cloning of Proof Reading Polymerase Chain Reaction Products Based on the Lethal ccdB Gene in Escherichia coli
}

\author{
Pascal Weibel $^{1 *}$, Miriam Ender ${ }^{\text {* }}$, Jerzy Madon ${ }^{1}$, Annelies S. Zinkernagel ${ }^{2}$, Reto A. Schuepbach ${ }^{1}$ \\ ${ }^{1}$ Surgical Intensive Care Medicine, University Hospital Zurich, University of Zurich, Zurich, Switzerland \\ ${ }^{2}$ Clinic of Infectious Diseases and Hospital Hygiene, University Hospital Zurich, University of Zurich, Zurich, Switzerland \\ Email: reto.schuepbach@usz.ch
}

Received December 14, 2012; revised January 15, 2013; accepted February 16, 2013

\begin{abstract}
Introducing PCR products into plasmids vectors is key for molecular techniques. Ideally cloning vectors are easy to construct, modify and propagate, neither require advanced techniques nor special equipment or reagents and efficiently incorporate PCR products at close to zero empty vector background. We provide an easy to engineer self-made cloning vector, neither requiring sophisticated tools or techniques nor advanced cloning knowledge. Through recombination we obtained the pUC18 $c c d B$ vector, carrying the $c c d B$ suicide gene within the pUC18 backbone. When SmaI cleaved (within the $c c d B)$ vector was T4 ligated with small $(0.2 \mathrm{kbp})$ and intermediate (1.3 to $2.2 \mathrm{kbp})$ blunt end PCR-products and transformed into E. coli, the amount of clones with incorporated PCR product was comparable to commercial PCR-cloning kits and at a close to zero PCR product negative background. In conclusion we present a simple, versatile and cheap approach to an efficient "home made" PCR-cloning vector that allows integration of crude blunt end PCR products at close to zero background.
\end{abstract}

Keywords: PCR-Cloning Vector; Blunt End; $c c d B$; Toxic Gene

\section{Introduction}

Cloning of polymerase chain reaction (PCR) products into plasmids of Escherichia coli (E. coli) is crucial for molecular techniques [1]. Numerous systems have been proposed and many have been commercialized allowing to introduce PCR products into plasmids. Most PCRcloning vectors share three key features: 1) incorporation of the PCR product into a circular plasmid DNA; 2) selection of $E$. coli clones that have incorporated the plasmid; and 3) selection of clones that contain the PCRproduct of interest [2].

For studies in which highest possible cloning efficiency is not essential, minimal workload would be desired such as direct cloning of blunt ended products from PCR reactions obtained by proof reading polymerase reactions. Ligation of such blunt ended DNA products lacking sticky ends or TA-overhangs however result in reduced ligation efficiency into the PCR cloning vector [3]. Thus efficient elimination of $E$. coli without plasmid uptake and removal of empty vector background through efficient selection of clones with incorporated PCR-products is required.

\footnotetext{
*These authors contributed equally to this article.
}

Selection for plasmid uptake is usually performed by encoding an antibiotic resistance gene within the PCR cloning plasmid [2]. When grown in the presence of antibiotics only bacteria carrying the plasmid encoding a matching resistance gene can survive. To further select for PCR-product incorporation numerous approaches with various efficiency and limitations have been used. Some need labor intensive procedures such as dephosphorylation of the linearized vector preventing religation unless a phosphorlylated DNA-fragment is interposed [4]. The use of a blunt end restriction site which is destroyed as a result of incorporating a PCR fragment has also successfully been used [5]. Alternatively the vector can be engineered such that incorporation of the PCR-product affects a selection marker. Either the gene itself or its promoter is disrupted and becomes dysfunctional after the insertion event [6]. A commonly used example of this selection technique is "blue/white selection" based on disruption of the $\beta$-galactosidase reporter gene [6,7]. Although this method became commercialized and is commonly used, this 'negative-selection' technique cannot be used in the presence of high background due to religation of non-recombinant clones. Alternatively toxic reporter genes were developed that allow direct elimination of 
non-recombinant clones resulting in efficient selection for vectors with incorporated DNA [8-11]. Such "positive-selections" can virtually eliminate empty vector plasmids carrying clones. One example of toxic genes used for positive-selection is the $c c d B$ gene product which traps gyrase and kills most $E$. coli strains [8] usually used for molecular techniques. As an exception strains carrying a mutation within DNA gyrase (gyrA462) are resistant to the $c c d B$ gene product $[12,13]$ and thus allow propagation of $c c d B$ carrying vectors.

Herein we describe a simple and cheap way to engineer and propagate a PCR-cloning vector which allows everybody to efficiently clone blunt ended PCR products with a close to zero background.

\section{Methods}

\subsection{Bacterial Strains and Plasmids}

We used the E. coli strains XL1Blue (Stratagene, CA) and $c c d B$ resistant One Shot ${ }^{\mathbb{R}} c c d B$ Survival ${ }^{\mathrm{TM}}$ (Invitrogen, NY) cells. Cells were grown in Luria-Bertani medium (LB) and rendered chemically competent by incubation on ice with TfB1 $\left(\mathrm{RbCl} 100 \mathrm{mM}, \mathrm{MnCl}_{2} .50 \mathrm{mM}\right.$, KOAc, $30 \mathrm{mM}, \mathrm{CaCl}_{2} .10 \mathrm{mM}$ and glycerol $15 \% \mathrm{v} / \mathrm{v}$ ) and TfB2 ( $\mathrm{RbCl} 100 \mathrm{mM}, \mathrm{CaCl}_{2} .10 \mathrm{mM}$, glycerol 15\% $\mathrm{v} / \mathrm{v})$ then frozen in liquid nitrogen until further used for transformation.

\subsection{Reagents}

DNA modifying enzymes were purchased from New England BioLabs (NEB; MA, USA); restriction enzymes used were BamH1, EcoR1, Pst1 and SmaI, polymerases used were Taq and Pfu Phusion and for DNA ligation T4 DNA ligase. All enzymes were used according to the recommendations of the manufactor in conjunction with recommended buffers. As a reference for PCR cloning efficiency commercial TA-cloning vector $\mathrm{pCR}^{\circledR} 2.1$ TOPO (Invitrogen) was used in conjunction with PCR products carrying 5'-A overhangs (resulting from incubation with Taq DNA polymerase). PCR cleanup and plasmid extraction kits were purchased from Macherey Nagel (Düren, Germany). LB and super Optimal Broth containing $20 \mathrm{mM}$ of glucose (SOC medium) were made and sterilized following standard protocols.

\subsection{Construction of the pUC18ccdB Cloning Plasmid}

$\mathrm{pDONR}^{\mathrm{TM}} 207$ (Invitrogen) was digested with Pst1 restriction sites and the agarose gel purified 1829 base pair (bp) $c c d B$ gene containing fragment was introduced into the single Pst1 cut pUC18 (Aligent, NL) using T4 DNA ligase (NEB) (Figure S1). To analyze the orientation of the $c c d B$ fragment incorporation diagnostic digests were performed. In clones in which the $c c d B$ and ampicillin resistance $(A m p R)$ genes were oriented in the same direction digestion with EcoRI and BamHI yielded a 725 bp fragment. The opposite orientation of the two genes yielded a $1161 \mathrm{bp}$ fragment (Figure S2). To eliminate one of the two SmaI restriction sites and to decrease plasmid size a 746 bp fragment was removed by EcoRI digestion of a clone in which $c c d B$ and $A m p R$ were aligned. The linear EcoRI cut 3769 bp long backbone was self-ligated (T4 ligase). The resulting circular modified pUC18 plasmid containing the $c c d B$ gene $(\mathrm{pUC} 18 c c d B)$ shown in Figure 1 was verified by sequencing, and functionality of the ampicillin and $c c d B$ genes were verified (Figure S3). pUC18 $c c d B$ was amplified in and isolated from One Shot $^{\mathbb{B}} c c d B$ Survival ${ }^{\mathrm{TM}}$ cells, purified then linearized by a single cut event in the $c c d B$ gen using the SmaI restriction enzyme. Linear pUC18ccdB was stored frozen until usage for PCR cloning.

\subsection{Synthesis of PCR Products for Cloning}

We generated a $237 \mathrm{bp}$ long PCR product using an alkaline phosphatase gene carrying plasmid [14,15], the primers provided in Table S1 and Pfu Phusion polymerase (NEB). PCR was carried out according to the manufactor's instructions. To make the PCR product also suited for TA-cloning a proportion of the PCR reaction mix was incubated 20 minutes at $70^{\circ} \mathrm{C}$ with Taq DNA polymerase and fresh dNTP (both from NEB). All PCR products were cleaned (NucleoSpin Extract $\Pi$ Kit; Macherey-Nagel) before T4 ligation reaction.

To generate larger PCR products, cDNA derived from mouse liver was amplified using Pfu Phusion (NEB) following the manufactor's instructions. Primer pairs used to generate the two $1.3 \mathrm{kbp}$ products (CDS encoding

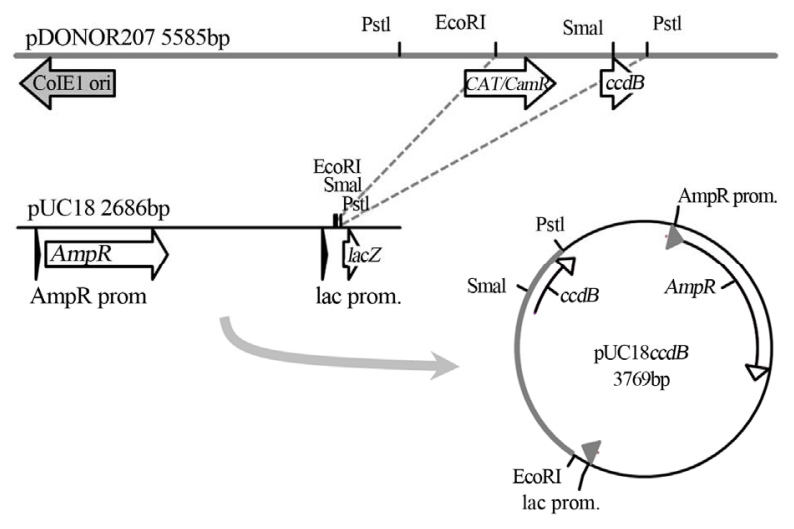

Figure 1. Scheme of pUC18, pDONR ${ }^{\mathrm{TM}} 207$ and pUC18ccdB vectors. Shown are the ampicilin resistance gene (AmpR) with promotor (AmpR prom.), the $\beta$-Galactosidase encoding gene (lacZ) with promotor (lac prom.), the canamycin resistance mediating gene $(C A T / C a m R)$ with promotor and the $c c d B$ suicide gene $(c c d B)$ targeting gyrase as well as restriction sites. 
protease activated receptor (PAR)-3 and PAR4) and the $2.2 \mathrm{kbp}$ product (CDS encoding thrombomodulin) are provided in Table $\mathbf{S} 1$.

\subsection{Analysis of DNA}

DNA was separated by $1 \%$ agarose gels, stained with ethidium bromide and analyzed using a CCD camera (BioRad, München, Germany). One kb ladder from Promega was used as reference. Commercial DNA sequencing was performed by Microsynth (Balgach, Switzerland).

\subsection{PCR Product Incorporation into Linear Plasmid and Transformation of Competent Cells}

Equal amounts ( $0.075 \mathrm{pmol})$ of SmaI linearized pUC18 $c c d B$ blunt ended PCR products were incubated over night at $16^{\circ} \mathrm{C}$ with T4 DNA ligase (NEB) according to the manufactor's instruction. As control reaction PCR cloning using the $\mathrm{pCR}^{\circledR}-\mathrm{XL}^{-} \mathrm{TOPO}^{\circledR}$ vector kit (Invitrogen) was used. The Manufactor's protocol was followed (30 minutes incubation of $1 \mu \mathrm{L}$ of $\mathrm{pCR}^{\circledR}-\mathrm{XL}^{\mathrm{T}} \mathrm{TOPO}{ }^{\circledR}$ vector reagent with $4 \mu \mathrm{L}$ of gel purified PCR product ( $\sim 0.6$ pmol) with deoxyadenosin 3' ends).

Either of the reaction products $(5 \mu \mathrm{L})$ were incubated 30 minutes on ice with $15 \mu \mathrm{L}$ of competent XL1Blue cells, heat shocked, then propagated in SOC medium $\left(37^{\circ} \mathrm{C}\right.$ shaking, 1 hour) and $20-100 \mu \mathrm{L}$ of transformed cells were plated on LB-agar plates containing $100 \mathrm{mg} / \mathrm{L}$ of ampicillin. Clones were picked and analyzed after 14 24 hours of incubation at $37^{\circ} \mathrm{C}$.

\subsection{Statistics}

Confidence intervals on proportion were calculated with aid of the NCSS software package based on F distribution.

\section{Results}

The hybrid plasmid $\mathrm{pUC} 18 c c d B$ was obtained by recombination of the commercial pUC18 and pDONOR207 plasmids followed by removal of the SmaI restriction site within the pUC18's multi cloning site (Figure 1). Sequencing excluded non desired mutations within the newly constructed $\mathrm{pUC} 18 \mathrm{ccdB}$ plasmid.

\subsection{Assessing Cloning Efficiency of a Small PCR Product in pUC18ccdB}

To test if pUC18ccdB can be used for direct cloning of PCR fragments we generated a blunt ended short (237 bp) PCR product and tested overall efficiency of incurporation within $\mathrm{pUC} 18 c c d B$. We inserted the $273 \mathrm{bp}$ PCR product into SmaI linearized pUC18ccdB. For compareson of efficiency the same PCR product was extended with 3'A-overhangs (incubation with Taq polymerase) and inserted into commercial $\mathrm{pCR}^{\circledR}$-XL-TOPO ${ }^{\circledR}$ vector. Reactions with either plasmid vector resulted in abundant transformants and all clones screened yielded the correctly inserted PCR fragment (Table 1).

\subsection{Utility of pUC18ccdB in Cloning Medium Size PCR Products}

PCR cloning vectors are often used for direct cloning of or introduction of mutations into already obtained coding sequences (CDS). We thus tested whether pUC18ccdB can be used to clone PCR products of mouse CDS ranging between 1.3 and $2.2 \mathrm{kbp}$ in size. Reaction conditions were used as described above and resulted in numerous transformants. These were screened for PCR product incorporation. We found all clones analyzed to have correctly incorporated both of the $1.3 \mathrm{kbp}$ PCR products (CDS of PAR3 and 4).Similarly in 6 out of the 7 clones analyzed the $2.2 \mathrm{kbp}$ CDS (encoding thrombomodulin) was present. The overall success rate for the $\mathrm{pUC} 18 \mathrm{ccd} B$ vector to provide a correctly incorporated medium sized PCR product was $94 \%$ (95\% confidence interval $\left(\mathrm{CI}_{95 \%}\right)$ $73 \%$ to $98 \%$ ) with a $100 \%\left(\mathrm{CI}_{95 \%} 63 \%\right.$ to $\left.100 \%\right)$ success rate for $1.3 \mathrm{~kb}$ PCR products and a $86 \%$ success rate $\left(\mathrm{CI}_{95 \%} 52 \%\right.$ to $99 \%$ ) for $2.2 \mathrm{kbp}$ PCR products (Table 2).

Our results demonstrate that short to mid-sized blunt end PCR fragments can efficiently be cloned into the $\mathrm{pUC} 18 c c d B$ vector at a close to zero empty vector background $[12,13]$.

\section{Discussion}

Through simple recombination of two commonly used and commercially available vectors we obtained the novel pUCccdB PCR cloning vector. In contrast to most commercial cloning vectors, this plasmid can easily be propagated without special reagents or equipment. In contrast to similar constructs made so far, which were more cumbersome to obtain, this plasmid can be made by research groups with limited budget and knowledge al-

Table 1. Yield of short PCR product containing transformants.

\begin{tabular}{ccccc}
\hline $\begin{array}{c}\text { PCR } \\
\text { fragment }\end{array}$ & Vector & $\begin{array}{c}\text { Colonies/ } \\
\text { plate }\end{array}$ & $\begin{array}{c}\text { Clones positive/ } \\
\text { analyzed }\end{array}$ & $\begin{array}{c}\mathrm{CI}_{0.95}[\%] \text { for PCR } \\
\text { product } \\
\text { incorporation }\end{array}$ \\
\hline $\begin{array}{c}\text { 237bp; } \\
\text { blunt }\end{array}$ & pUCccdB & $>20$ & $6 / 6$ & $60-100$ \\
$\begin{array}{c}\text { 237bp with } \\
\text { 3'-A } \\
\text { overhangs }\end{array}$ & $\begin{array}{c}\text { pCR }{ }^{\circledR} 2.1- \\
\text { TOPO }\end{array}$ & $>20$ & $3 / 3$ & $40-100^{*}$ \\
\hline
\end{tabular}

\footnotetext{
${ }^{*}$ Expected yield of $80 \%$ according to manufactor.
} 
Table 2. Yield of intermediate sized PCR product containing transformants.

\begin{tabular}{cccc}
\hline PCR fragment & Vector & $\begin{array}{c}\text { Positive/ } \\
\text { analyzed } \\
\text { clones }\end{array}$ & $\begin{array}{c}\mathrm{CI}_{0.95}[\%] \text { for PCR } \\
\text { product } \\
\text { incorporation }\end{array}$ \\
\hline $\begin{array}{c}\text { CDS (PAR3), } \\
1.3 \text { kbp, blunt }\end{array}$ & pUC18ccdB & $7 / 7$ & $63-100$ \\
$\begin{array}{c}\text { CDS (PAR4), } \\
1.3 \text { kbp, blunt } \\
\begin{array}{c}\text { CDS } \\
\text { (Thrombomodulin), }\end{array}\end{array}$ & pUC18ccdB & $7 / 7$ & $63-100$ \\
2.2 kbp, blunt & & & \\
\hline
\end{tabular}

lowing them to easily rebuild this versatile PCR cloning vector.

Many vectors from commercial PCR-cloning kits such as the TOPO ${ }^{\circledR}$ or PCR $2.1^{\circledR}$ series are marketed as linearized vectors thus precluding amplification and modification. In contrast to these, $\mathrm{pUC} c c d B$ can easily be amplified in commercially available E. coli $[12,13]$ carrying the gyrA462 mutation. This opens up possibilities for modification of the $c c d B$ selection gene [16] or the vector backbone and thus further adds to versatility. Rebuilding of pUCccdB along the lines we propose only relies on very basic PCR and cloning skills and limited labor.

We have compared cloning efficiency of pUC18ccdB with the commercially available highly efficient PCR cloning kit $\mathrm{pCR}^{\circledR} 2.1$-TOPO. Whereas $\mathrm{pUC} 18 c c d B$ relies on positive selection through disruption of the $c c d B$ suicide gene, $\mathrm{pCR}^{\mathbb{B}} 2$.1-TOPO relies on vaccinia virus derived topoisomerase I. This enzyme binds to the vector, cleaves the phosphodiester backbone after 5'-CCCTT at either end of the linearized vector [17] to then bind both the backbone and the 3'-A of the PCR product before efficiently ligating the two ends. We found both methods to be highly efficient and to result in aboundant transformants with incorporated PCR products. Incorporation depending on topoisomerase I however requires an additional reaction step following amplification of the PCR product, i.e. the addition of 3' A overhangs by incubation with Taq polymerase.

An important characteristic of positive selection systems is the tightness of suppression in transformants that failed PCR product incorporation while offering efficient deletion of the selection marker upon incorporation of the PCR product. Excellent suppressive proprieties of the $c c d B$ gene product are underscored by the fact that this marker is widely used [8] and has been commercialized (e.g. gateway vector family; Invitrogen). Efficient selection of transformants with incorporated PCR plasmids however also requires successful disruption of the suicide gene upon PCR product incorporation. Multiple mechanisms blunt the gene product function and include premature introduction of a stop codon [4], introduction of a frame shift altering the gene product 3' of the incorporation site [4] or introduction of an additional protein stretch within the $c c d B$ gene product. Whereas the first two mechanisms destroy $c c d B$ gene products, simple introduction of additional amino acids might not. To address this issue we have designed our 237 bp PCR product such that it did 1) neither introduce a frame shift nor; 2) introduce a premature stop codon but simply inserted 79 amino acids between proline $e^{28}$ and glycine ${ }^{29}$ of the $c c d B$ gene product. We showed that the addition of these 79 amino acids was sufficient to destroy the function of the $c c d B$ gene product and that additional removal of the gene product 3' of the SmaI restriction site was not mandatory.

In conclusion, we describe a simple and cheap way to engineer and propagate an efficient, versatile "home made" cloning vector that allows efficient cloning of blunt ended small to medium sized PCR-products without requirement of advanced skills, special equipment nor reagents.

\section{Acknowledgements}

This work was supported by the Swiss National Foundation (grant\# PZ00P3 136639), the Faculty of Medicine and the Zentrum für Klinische Forschung of the University of Zurich, Zurich, Switzerland.

\section{REFERENCES}

[1] S. N. Cohen, "Bacterial Plasmids: Their Extraordinary Contribution to Molecular Genetics," Gene, Vol. 135, No. 1-2, 1993, pp. 67-76. doi:10.1016/0378-1119(93)90050-D

[2] O. Tolmachov, "Designing Plasmid Vectors," Methods in Molecular Biology, Vol. 542, 2009, pp. 117-129. doi:10.1007/978-1-59745-561-9 6

[3] B. Guo and Y. Bi, "Cloning PCR Products. An Overview," Methods in Molecular Biology, Vol. 192, 2002, pp. 111119.

[4] J. Sambrook, E. F. Fritsch and T. Maniatis, "Molecular Cloning: A Laboratory Manual," Spring Harbor Laboratory Press, New York, 1989.

[5] Z. G. Liu and L. M.Schwartz, "An Efficient Method for Blunt-End Ligation of PCR Products," Biotechniques, Vol. 12, No. 1, 1992, pp. 28-30.

[6] A. Ullmann, "Complementation in Beta-Galactosidase: from Protein Structure to Genetic Engineering," Bioessays, Vol. 14, No. 3, 1992, pp. 201-205. doi:10.1002/bies.950140311

[7] J. Vieira and J. Messing, "The pUC Plasmids, an M13mp7Derived System for Insertion Mutagenesis and Sequencing with Synthetic Universal Primers," Gene, Vol. 19, No. 3, 1982, pp. 259-268. doi:10.1016/0378-1119(82)90015-4

[8] P. Bernard, P. Gabant, E. M. Bahassi and M. Couturier, "Positive-Selection Vectors Using the F Plasmid ccdB 
Killer Gene," Gene, Vol. 148, No. 1, 1994, pp. 71-74. doi:10.1016/0378-1119(94)90235-6

[9] B. Henrich and B. Schmidtberger, "Positive-Selection Vector with Enhanced Lytic Potential Based on a Variant of Phi X174 Phage Gene E," Gene, Vol. 154, No. 1, 1995, pp. 51-54.

[10] P. Kast, "pKSS-A Second-Generation General Purpose Cloning Vector for Efficient Positive Selection of Recombinant Clones," Gene, Vol. 138, No. 1-2, 1994, 109114. doi:10.1016/0378-1119(94)90790-0

[11] S. A. Yazynin, S. M. Deyev, M. Jucovic and R. W. Hartley, "A Plasmid Vector with Positive Selection and Directional Cloning Based on a Conditionally Lethal Gene," Gene, Vol. 169, No. 1, 1996, pp. 131-132.

[12] D. F. Gruber, V. A. Pieribone, B. Porton and H. T. Kao, "Strict Regulation of Gene Expression from a High-Copy Plasmid Utilizing a Dual Vector System," Protein Expression and Purification, Vol. 60, No. 1, 2008, pp. 5357.

[13] P. Bernard and M. Couturier, "Cell Killing by the F Plasmid $c c d B$ Protein Involves Poisoning of DNA-Topoiso- merase П Complexes," Journal of Molecular Biology, Vol. 226, No. 3, 1992, pp. 735-745.

[14] R. A. Schuepbach, J. Madon, M. Ender, P. Galli and M. Riewald, "Protease Activated Receptor-1 Cleaved at R46 Mediates Cytoprotective Effects," Journal of Thrombosis and Haemostasis, 2012. doi:10.1111/j.1538-7836.2012.04825.x

[15] R. A. Schuepbach and M. Riewald, "Coagulation Factor Xa Cleaves Protease-Activated Receptor-1 and Mediates Signaling Dependent on Binding to the Endothelial Protein C Receptor," Journal of Thrombosis and Haemostasis, Vol. 8, No. 2, 2010, pp. 379-388.

[16] K. Miyazaki, "Lethal $c c d B$ Gene-Based Zero-Background Vector for Construction of Shotgun Libraries," Journal of Bioscience and Bioengineering, Vol. 110, No. 3, 2010, pp. 372-373.

[17] S. Shuman, "Recombination Mediated by Vaccinia Virus DNA Topoisomerase I in Escherichia coli Is Sequence Specific," Proceedings of National Academy of Science of USA, Vol. 88, No. 22, 1991, pp. 10104-10108. doi:10.1073/pnas.88.22.10104 


\section{Supplement}

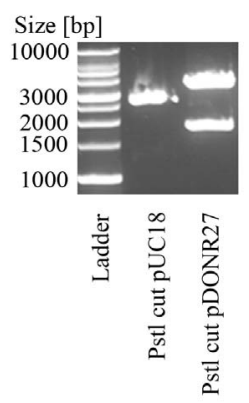

Figure S1. Gel electrophoresis of PstI cut vectors pUC18 and $\mathrm{pDONR}^{\mathrm{TM}} 207$. Following restriction enzyme digest DNA fragments were separated by agar gel electrophoresis and visualized using ethidium bromide. 1 kb DNA Ladder is shown as reference.

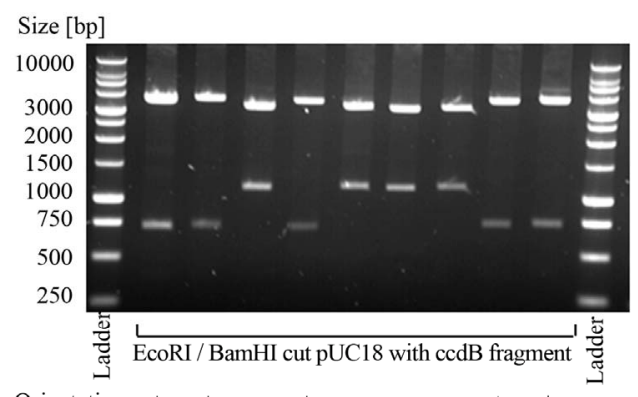

Orientation: ++

Plasmid in + orientation ( $A m p R$ and $c c d B$ in same orientation)

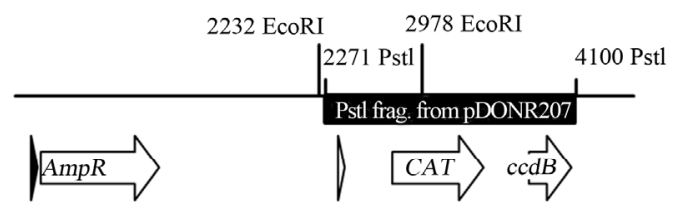

Plasmid in - orientation ( $A m p R$ and $c c d B$ in same orientation)

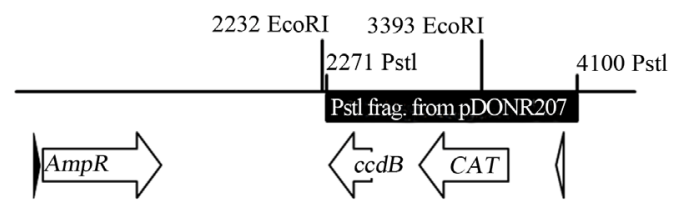

Figure S2. Incorporation of the $c c d B$ containing fragment removed from pDONOR ${ }^{\mathrm{TM}} 207$ through PstI digest and incorporation into PstI linearized pUC18. Recombination of PstI cut pUC18 with the $c c d B$ fragment. Visualized are EcoRI/BamHI digested recombinants (upper part) with schemes (lower part) showing the two possible orientations of $c c d B$ fragment incorporation.

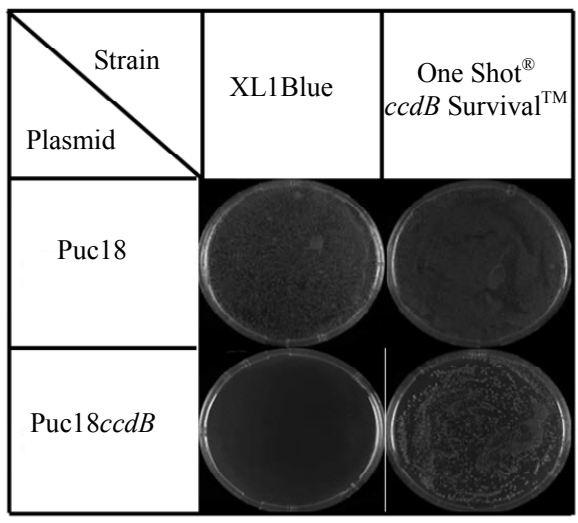

Figure S3. Plasmid transformation of XL1Blue and One Shot ${ }^{\circledR}$ ccdB Survival ${ }^{\mathrm{TM}}$ chemically competent cells. Cells were transformed with indicated plasmids and cultivated on ampicillin containing LB plates. 
Table S1. Primer sequences used for polymerase chain reaction.

\begin{tabular}{ccc}
\hline Gene product & GenBank accession & Primer 5' $\rightarrow$ 3' (added restriction site in italic) \\
\hline $\begin{array}{c}\text { Fragment of alkaline } \\
\text { phosphatase }\end{array}$ & NM_001632 & $\begin{array}{c}\text { fw: GCTACGCAGCTCATCTCCAAC } \\
\text { rev: GAGATGGGTCACAGACGGGT }\end{array}$ \\
$\begin{array}{c}\text { Protease activated } \\
\text { receptor 3 (PAR3) }\end{array}$ & NM_010170 & $\begin{array}{c}\text { fw: GCTAAAGCTTCACTTGCTGCTCATACATGGAGC } \\
\text { rev: GCTACTCGAGGGTGCCATGCACAAGTCAGCCAAGC }\end{array}$ \\
$\begin{array}{c}\text { Protease activated } \\
\text { receptor 4 (PAR4) }\end{array}$ & NM_007975 & $\begin{array}{c}\text { fw: GCTAAAGCTTGATCCTGGCAGCATGTGCTGGCCG } \\
\text { rev: GCTACTCGAGTCCTGAGGGTTCAAGAGGGATGTAG }\end{array}$ \\
$\begin{array}{c}\text { Thrombomodulin } \\
\text { fw: GCTAAAGCTTGTGATAGAGGCTAGCTGCTGT } \\
\text { rev: GCTACTCGAGGGATCTCCGCTGTATTTGCC }\end{array}$
\end{tabular}

